\title{
Investing into climate change mitigation despite the risk of failure
}

\section{Mike Farjam $^{1,2}$ (D) . Olexandr Nikolaychuk ${ }^{3}$. Giangiacomo Bravo ${ }^{1,2}$}

Received: 23 October 2018 / Accepted: 25 April 2019 / Published online: 9 May 2019

(C) The Author(s) 2019

\begin{abstract}
In order to convince both policy makers and the general public to engage in climate change mitigation activities, it is crucial to communicate the inherent risks in an effective way. Due to the complexity of the system, mitigation activities cannot completely rule out the possibility of the climate reaching a dangerous tipping point but can only reduce it to some unavoidable residual risk level. We present an online experiment based on a sample of US citizens and designed to improve our understanding of how the presence of such residual risk affects the willingness to invest into climate change mitigation. We found that, far from reducing them, the presence of residual risk actually increases investments into mitigation activities. This result suggests that scientists and policy makers should consider being more transparent about communicating the residual risks entailed by such initiatives.
\end{abstract}

\section{Introduction}

Public support and design of climate policies is strongly affected by how individuals and organizations perceive the associated costs and risks (IPCC 2014; Sterman 2008). Due to the complexity of the system, current mitigation activities cannot completely rule out the possibility of the climate reaching a dangerous tipping point but can only reduce it to some unavoidable residual risk level (Holden et al. 2018; Steffen et al. 2018; Lenton 2011). Effective communication of both mitigation initiatives and of risks linked to various degrees of the temperature increase above the pre-industrial level therefore presents a crucial challenge for scientists and policy makers (Morgan et al. 2002), as recently highlighted by the IPCC report of the consequences of a "limited" global warming of $1.5^{\circ} \mathrm{C}$ above the pre-industrial

Electronic supplementary material The online version of this article (https://doi.org/10.1007/s10584-019-02454-1) contains supplementary material, which is available to authorized users.

\footnotetext{
Mike Farjam

Mike.Farjam@lnu.se
}

1 Department of Social Studies, Linnaeus University, Växjö, Sweden

2 Linnaeus University Centre for Data Intensive Sciences, Applications, Växjö, Sweden

3 Faculty of Economics and Business Administration, Friedrich Schiller University, Jena, Germany 
level (IPCC 2018). In addition, mitigation behaviour is affected by the information available as well as by the framing of the problem channelled trough traditional and social media (Boykoff 2011; Morton et al. 2011).

Several experimental papers studied how risk and ambiguity affect the willingness to contribute in games modelling collective action as a means to solve climate dilemmas, generally reporting higher contributions when the risk of disastrous losses increased (Milinski et al. 2008; Barrett and Dannenberg 2014; Tavoni et al. 2011). However, those works only considered the risk linked to the failure of preventing further climate change, without considering that humanity would suffer certain consequences of climate change even in the best-case scenario of the international collaboration succeeding in limiting global warming to around $1.5^{\circ} \mathrm{C}$ (IPCC 2018). Farjam et al. (2018) distinguished between an a priori and a residual risk, the former referring to the consequences of an unsuccessful collective action (e.g., not limiting the increase of the temperature to $1.5-2{ }^{\circ} \mathrm{C}$ above pre-industrial levels, as stated by the 2009 Paris Agreement), the latter referring to the risk that cannot be ruled out even in case of a successful collective action (e.g., due to the climate inertia). It is also important to note that the residual risk discussed here is different from what is sometimes referred to as threshold ambiguity, i.e., what level of greenhouse gases concentration is going to trigger positive feedback loops leading to a self-sustaining climate change (Holden et al. 2018; Stocker 2013). Under threshold ambiguity, it is possible for an optimistic decision-maker to expect the required level of effort to be lower than under certainty. Indeed, previous experimental research found that threshold ambiguity reduced contributions to climate change mitigation relative to the certainty condition (Barrett and Dannenberg 2014; Dannenberg et al. 2015). On the other hand, a scenario with residual risk compared with one without does not allow for such optimism, which makes it rational to perceive the former as more threatening. In line with this logic, Farjam et al. (2018) showed that residual risk in the context of climate change mitigation activities could actually increase contributions in a collective-risk social dilemma (CRSD) game (Milinski et al. 2008) where the participants had the choice either to keep their endowment for themselves or to contribute part of it to a common "climate account." If after 10 rounds the total group contribution was lower than a predefined (and known) threshold, the group faced the ( $a$ priori) risk of a large monetary loss, emulating the consequences of climate change. The surprising, albeit preliminary result of their study was that, everything else being equal, the participants generally invested more and reached the threshold more frequently when a low but positive level of residual risk was present in the game (Farjam et al. 2018).

In other words, we found evidence that a moderate level of residual does not reduce the willingness to invest in climate change mitigation but actually may increase it. The main goal of the current work was to validate and extend this result to a broader range of levels of residual risk, all using a larger and more representative pool of participants. This also enabled us to investigate if the relationship between the level of residual risk and individual contributions to the climate account is actually linear. Taking into account both the findings in Farjam et al. (2018) and the relation between the various levels of $a$ priori and residual risk, we expected an inverted U-shaped relationship between the level of residual risk and contributions, i.e., the highest level of contributions would be attained at intermediate levels of residual risk. If residual risk was negligible, the participants would essentially be in a situation where only a priori risk mattered whereas if residual risk was too high, the improvement over the a priori risk scenario would become insufficient to motivate the contributions. 


\section{Methods}

In our experiment, the CRSD was played in a group of 6 participants who had 10 rounds to provide a total contribution of 120 experimental currency units (ECU) to the climate account. Each participant had an initial endowment of 40 ECU and could contribute $\{0,2,4\}$ ECU to the climate account in each round. At the end of each round, the participants learned the complete contribution profile of the others. What remained of their endowment by the end of the game was automatically credited to their private account.

In all treatments, the level of a priori risk was kept fixed at 0.9 to allow for a broad range of meaningful levels of residual risk, which were set to $\pi \in\{0.0,0.1,0.2,0.3,0.4\}$ depending on the treatment (labelled RR0-RR4, respectively). At the end of the game, the total group contribution determined the type of risk the group faced: a priori risk if it was lower than 120 ECU or residual risk otherwise. The potential payoff equalled the amount left on the private account while the relevant level of risk determined the probability with which that amount would be reduced to zero. It is worth noting that the investments into the climate account did have real-world consequences as the accumulated funds were used to finance carbon offset initiatives (this was clearly stated in the experiment instructions). Altogether, the participants contributed an equivalent of 1480 USD to the climate account, which was used to offset $3700 \mathrm{t}$ of $\mathrm{CO}_{2}$ via the United Nations platform for voluntary cancellation of certified emission reductions (CERs).

The participants were adult US residents recruited via the crowd-sourcing platform Mechanical Turk (MTurk), and the experiment was programmed using oTree (Chen et al. 2016). The sessions were conducted between November 27 and December 4, 2017. All treatment conditions were run between-subject. The game was framed in terms of experimental currency units that were subsequently translated into real money using a conversion rate of 10 ECU per 1 USD. The average payment was 3.1 USD (including a show up fee of 1.3 USD), a relatively high amount as far as MTurk standards, for an average duration of 12 minutes. Altogether, 165 groups participated in the experiment, for a total of 990 subjects. Groups with any members dropping out during the course of the experiment were excluded, as well as one group exhibiting a strong outlier behaviour (the threshold was reached in round 7 but two participants continued contributing 4 ECU per round thereafter). The data presented in this paper hence include 149 groups for a total of 894 subjects.

All participants received on-screen instructions identical to those in Farjam et al. (2018), which included a brief explanation of the problem of global warming and use of the funds contributed to the climate account to purchase carbon compensation credits. As a means of control and also to decrease the probability of software bots being used, the participants had to answer at least 3 out of 7 comprehension questions correctly to play the game. ${ }^{1}$ If qualified, they played 10 rounds of the CRSD followed by a short questionnaire eliciting their political orientation and environmental attitude using items derived from the World Values Survey Association (2014).

\section{Results}

The data and $R$ (Core Team 2018) script on which our analysis is based can be downloaded from the Harvard Dataverse (https://doi.org/10.7910/DVN/SRT6BR).

\footnotetext{
${ }^{1}$ Only 1 participant out of 180 failed to do that in Farjam et al. (2018) so we do not consider the benchmark to be high at all.
} 
Table 1 provides an overview of the results for each treatment. Most groups succeeded in reaching the threshold, with only limited variation in total contributions. This result is consistent with previous works reporting a larger share of groups reaching the threshold under high a priori risk than in the original Milinski et al. (2008) experiment (Dannenberg et al. 2015; Tavoni et al. 2011).

To account for the fact that in the CRSD game the participants have to make decisions repeatedly before the outcome becomes evident, instead of taking the contributions at their face value, we followed the previous research in considering the cumulative distance from the reference contribution as our dependent variable (Farjam et al. 2018). The distance from the reference was computed for each group and round as:

$$
\Delta_{g, t}=\sum_{i=1}^{t} \sum_{j=1}^{6} C_{j, g, t}-12 t,
$$

where $g$ and $t$ represent the group and round, and $C_{j, g, t} \in\{0,2,4\}$ stands for the contribution of subject $j$, as a member of group $g$, in round $t$. The number 12 represents the average group contribution in each round sufficient to reach the threshold of $120 \mathrm{ECU}$ by the end of the game.

One key advantage of this metric is that it makes it clear if a given group is "on track" during the course of the game, and it also alleviates the problem of heteroscedasticity as the result of the potential growth of the climate account over time.

Figure 1 illustrates that the general contribution patterns were similar across all the treatments, with the distance from the reference increasing in the early rounds of the game but decreasing towards the end. In addition, the distance was larger in all of the residual risk treatments (RR1-RR4) when compared to the baseline level of no residual risk in RR0, with RR1 and RR2 showing the highest contribution levels.

In order to test the statistical significance of our findings, we estimated the model presented in (2), using the distance from the reference as the dependent variable. To control for the common time trend, $\lambda_{t}$ represents the LOESS spline of the distance from the reference averaged across all groups and treatments (the smoothing parameter $\alpha$ set to the default value (Shyu et al. 2017). The level of residual risk $\pi$, along with the political orientation and environmental attitude of the participants (average values at the group level), was used as the independent variables. To check our hypothesis of a non-linear relationship between the level of residual risk and distance from the reference, we also included a quadratic term for $\pi$ in the model (Table 2). Other non-systematic differences across the groups were modelled as a random effect $\epsilon_{g}$.

$$
\Delta_{g, t}=\lambda_{t}+\beta_{1} \pi+\beta_{2} \pi^{2}+\beta_{3} \text { pol }_{g}+\beta_{4} \text { env } v_{g}+\epsilon_{g}+\epsilon_{g, t}
$$

Table 1 Summary results per treatment; $\pi$ represents the level of residual risk

\begin{tabular}{llll}
\hline Treatment & Groups & $\begin{array}{l}\text { Threshold } \\
\text { reached }\end{array}$ & $\begin{array}{l}\text { Average group } \\
\text { contribution }\end{array}$ \\
\hline $\operatorname{RR} 0(\pi=0.0)$ & 27 & $93 \%$ & $122.8(\mathrm{sd}=11.6)$ \\
$\operatorname{RR} 1(\pi=0.1)$ & 29 & $97 \%$ & $124.8(\mathrm{sd}=6.2)$ \\
$\operatorname{RR} 2(\pi=0.2)$ & 35 & $92 \%$ & $124.1(\mathrm{sd}=10.0)$ \\
$\operatorname{RR} 3(\pi=0.3)$ & 28 & $89 \%$ & $122.1(\mathrm{sd}=13.7)$ \\
$\operatorname{RR} 4(\pi=0.4)$ & 30 & $90 \%$ & $123.0(\mathrm{sd}=6.9)$ \\
\hline
\end{tabular}




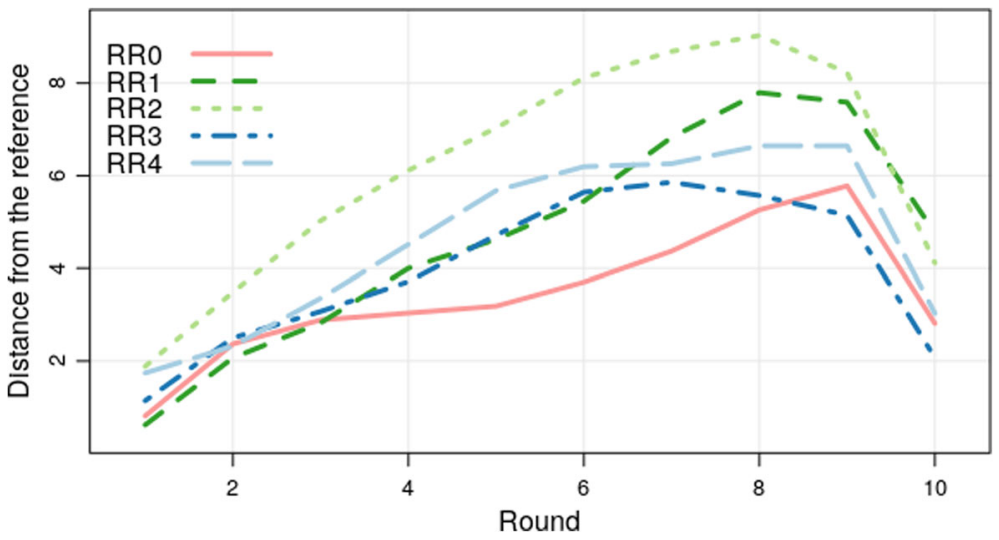

Fig. 1 Average distance from the reference per treatment and round

To fit the model in (2), we adopted the Bayesian framework with vague priors and estimated the posterior distributions of the parameters using JAGS. The results were based on sampling from four independent chains with $5000+10,000$ samples each.

In line with our expectations, we found (i) a positive coefficient estimate at $\pi$ and (ii) a negative coefficient estimate at $\pi^{2}$, implying an inverted U-shaped relationship between the group contribution and level of residual risk. In addition, the contributions were lower from the participants identifying themselves as leaning right-wing and those less concerned about the environment. According to the standard significance criteria (Kass and Raftery 1995), the evidence is strong for hypothesis (i) and positive for hypothesis (ii). The level or residual risk $\pi$ resulting in the highest level of contributions is estimated to be slightly above $20 \%,^{2}$ thus lying in the middle of the range of $\pi$ considered by us.

\section{Discussion}

We found robust evidence that low-to-moderate levels of residual risk do not discourage people from investing into climate change mitigation activities but actually increase their willingness to do so. These results corroborate the earlier findings of Farjam et al. (2018) by using a much larger and representative sample of US residents as well as a broader range of levels of residual risk. The fact that the climate debate is especially heated in the USA, where political ideology correlates with climate scepticism (Hornsey et al. 2018; Farjam et al. 2019), adds to the interest and validity of our findings. This is also reflected in the estimated coefficients at our control variables that indicate that the participants' contributions were affected by their political and environmental preferences, which further extends the results of recent research (Hornsey et al. 2018) by providing an actual behavioural measure as opposed to self-declared attitudes and intentions typically elicited in surveys (recall that, in our case, the contributions had actual real-world consequences).

It is worth noting that the values of the parameters used in the experiment are in line with the prevalent climate modelling: the a priori risk of $90 \%$ reflects the "likely" disastrous effects of the baseline climate scenario in the latest IPCC report (IPCC 2014), whereas the

\footnotetext{
${ }^{2}$ This is the value of $\pi$ that maximizes Eq. 2 given the estimates in Table 2 . The corollary of that is that larger values of $\pi$ have a negative effect on the contributions.
} 
Table 2 Bayesian coefficient estimates for the distance from the reference model

\begin{tabular}{lrllll}
\hline & $\beta$ & $\mathrm{CI}_{95}$ & $\begin{array}{l}\text { Effective } \\
\text { sample size }\end{array}$ & $\begin{array}{l}\text { Convergence } \\
(\text { PSRF })\end{array}$ & $\begin{array}{l}\text { Odds } \\
(\beta>0)\end{array}$ \\
\hline$\pi$ & 16.9 & {$[0.55,32.81]$} & 82 & 1.04 & $58: 1$ \\
$\pi^{2}$ & -36.4 & {$[-80.37,12.40]$} & 83 & 1.04 & $1: 15$ \\
Left/right scale & -1.4 & {$[-2.56,-0.25]$} & 914 & 1.01 & $1: 110$ \\
Environmental concern & 1.3 & {$[0.05,2.46]$} & 860 & 1.01 & $44: 1$ \\
$R^{2}$ & 0.67 & & & & \\
\hline
\end{tabular}

$R^{2}$ (sample mean) is calculated following Gelman et al. (2018)

residual risk of $10-20 \%$ reflects what is estimated to be the likely damage to many sectors of the US economy even in case of a successful implementation of the Paris Agreement, i.e., keeping the global average temperature increase below $2{ }^{\circ} \mathrm{C}$ (Hsiang et al. 2017). More generally, the range of residual risk explored in the experiment corresponds to outcomes labelled as "very unlikely" or "unlikely" in IPCC (2010) reports. Existing research suggests that the public usually misinterprets such qualitative labels (Budescu et al. 2014; Teigen et al. 2013). Therefore, policy makers may want to be more explicit about the numerical range of residual risk to maximize its positive effect on the willingness to engage in mitigation activities. For instance, there are several instances in the recent report on Global Warming of $1.5^{\circ} \mathrm{C}$ where it is stated that emissions from the pre-industrial period to the present day (i.e., in the absence of further emissions) are unlikely to cause a global warming of $1.5{ }^{\circ} \mathrm{C}$, which somewhat obscures the fact that there is a probability of up to $33 \%$ that such an increase in the temperature can actually occur.

A limitation of our experimental setting is acknowledged by the fact that contributions to climate change mitigation in the real world often fall below self-set goals, whereas in our experiment, due to the high level of a priori risk of $90 \%$ in all treatments, most groups managed to reach the threshold required to reduce the risk of losing everything. This difference in contributions between the real world and the experiment may also be due to the relatively short time span considered in the CRSD game (10 min compared with decades in the real world) as well as the clarity of the rules of the game compared with the uncertainty intrinsic to the real climate debate.

When interpreting our findings, one has to be aware of these simplifications, and more research on the generalizability of the observed effect of residual risk is definitely needed. This word of caution becomes even more relevant when taking into account recent discussions on the measurement of risk preferences, which point out that different ways of measuring such preferences only lead to vaguely correlated estimates (Pedroni et al. 2017).

Standard theories of individual decision-making as well as common sense would suggest that situations with residual risks of negative events are less desirable than alternatives without such risks (Pratt 1992). Less obviously, unavoidable residual risk might lead to stress or a heightened state of alertness in decision makers, such that the threat would appear more immediate. On the one hand, existing evidence suggests that under stress, people tend to focus on how things can go right instead of on the negative outcomes (Mather and Lighthall 2012). On the other hand, stress tends to distort the perception of risks, and high levels of stress positively correlate with risk aversion (Kandasamy et al. 2014). Furthermore, while the majority of research on decision-making focuses on individual behaviour and outcomes, climate change mitigation represents a collective action problem for humanity as a whole, which makes the situation difficult to analyze theoretically (see Farjam et al. 2018). 
Empirical work, like the one presented in this paper, could play an important role in discovering factors promoting mitigation behaviours, and thus help practitioners and policy makers to devise better approaches and guidelines. Our findings actually challenge the intuition that, simply because some climate change mitigation course appears worse in terms of expected gains (in our case, because of some residual risk of failure involved), the actors are less motivated to contribute to its realization. This has been done before both on conceptual grounds (Morton et al. 2011; Santos and Pacheco 2011) and experimentally (Farjam et al. 2018). However, the results presented here are based on a superior sample of participants, engaging the residents of the country that is a crucial player as far as the future of climate, and thus have unambiguous implications for scientists and policy makers alike. Transparent communication of climate science findings, including the fact that the risk of a disastrous climate change cannot completely be ruled out by reaching internationally agreed upon goals (Holden et al. 2018; Steffen et al. 2018; Lenton 2011), such as the limit of $+2{ }^{\circ} \mathrm{C}$ over the pre-industrial average temperatures, not only will not backfire but also can even motivate people to increase their mitigation efforts.

Acknowledgments The research presented in this article was supported by the Linnaeus University Center for Data Intensive Sciences and Applications, DISA (http://lnu.se/disa). The authors gratefully acknowledge the comments and suggestions from the participants of the 2018 World Meeting of the Economic Science Association and the 2018 Meeting of the Italian Association of Environmental and Resources Economists.

Author Contributions M.F., O.N., and G.B. planned the research, discussed the results and wrote the paper. M.F. and O.N. coded and conducted the experiment and analyzed the data.

Open Access This article is distributed under the terms of the Creative Commons Attribution 4.0 International License (http://creativecommons.org/licenses/by/4.0/), which permits unrestricted use, distribution, and reproduction in any medium, provided you give appropriate credit to the original author(s) and the source, provide a link to the Creative Commons license, and indicate if changes were made.

\section{References}

Barrett S, Dannenberg A (2014) Sensitivity of collective action to uncertainty about climate tipping points. Nat Clim Chang 4:36-39. https://doi.org/10.1038/nclimate2059

Boykoff MT (2011) Who speaks for the climate?: Making sense of media reporting on climate change. University Press, Cambridge

Budescu DV, Por HH, Broomell SB, Smithson M (2014) The interpretation of ipcc probabilistic statements around the world. Nat Clim Chang 4(6):508

Chen DL, Schonger M, Wickens C (2016) oTree: An open-source platform for laboratory, online, and field experiments. J Behav Exp Financ 9:88-97

Core Team R (2018) R: a language and environment for statistical computing. R Foundation for Statistical Computing. Vienna, Austria. https://www.R-project.org/

Dannenberg A, Löschel A, Paolacci G, Reif C, Tavoni A (2015) On the provision of public goods with probabilistic and ambiguous thresholds. Environ Resour Econ 61(3):365-383. https://doi.org/10.1007/s10640014-9796-6

Farjam M, Nikolaychuk O, Bravo G (2018) Does risk communication really decrease cooperation in climate change mitigation? Clim Chang 149(2):147-158

Farjam M, Nikolaychuk O, Bravo G (2019) Experimental evidence of an environmental attitude-behavior gap in high-cost situations, socArXiv

Gelman A, Goodrich B, Gabry J, Vehtari A (2018) R-squared for bayesian regression models. Am Stat 0:1-6

Holden P, Edwards N, Ridgwell A, Wilkinson R, Fraedrich K, Lunkeit F, Pollitt H, Mercure JF, Salas P, Lam A, Knobloch F, Chewpreecha U, Vinuales J (2018) Climate-carbon cycle uncertainties and the paris agreement. Nat Clim Chang 8:609-613. https://doi.org/10.1038/s41558-018-0197-7 
Hornsey MJ, Harris EA, Fielding KS (2018) Relationships among conspiratorial beliefs, conservatism and climate scepticism across nations. Nat Clim Chang 8(7):614-620. https://doi.org/10.1038/s41558-0180157-2

Hsiang S, Kopp R, Jina A, Rising J, Delgado M, Mohan S, Rasmussen DJ, Muir-Wood R, Wilson P, Oppenheimer M, Larsen K, Houser T (2017) Estimating economic damage from climate change in the united states. Science 356(6345):1362-1369. https://doi.org/10.1126/science.aal4369. http://science. sciencemag.org/content/356/6345/1362.full.pdf

IPCC (2010) Guidance note for lead authors of the IPCC fifth assessment report on consistent treatment of uncertainties, https://wg1.ipcc.ch/guidancepaper/ar5_uncertainty-guidance-note.pdf, iPCC CrossWorking Group Meeting on Consistent Treatment of Uncertainties

IPCC (2014) Climate change 2014: Mitigation of climate change. summary for policymaker, working Group III Contribution to the IPCC Fifth Assessment Report

IPCC (2018) Global warming of $1.5^{\circ} \mathrm{C}$ : an IPCC special report on the impacts of global warming of $1.5^{\circ}$ above pre-industrial levels and related global greenhouse gas emission pathways, in the context of strengthening the global response to the threat of climate change, sustainable development, and efforts to eradicate poverty, https://www.ipcc.ch/sr15/, working Group III Contribution to the IPCC Fifth Assessment Report

Kandasamy N, Hardy B, Page L, Schaffner M, Graggaber J, Powlson AS, Fletcher PC, Gurnell M, Coates J (2014) Cortisol shifts financial risk preferences. Proc Natl Acad Sci 111(9):3608-3613

Kass RE, Raftery AE (1995) Bayes factors. J Am Stat Assoc 90(430):773-795

Lenton TM (2011) Early warning of climate tipping points. Nat Clim Chang 1(4):201-209. https://doi.org/10. 1038/nclimate1143

Mather M, Lighthall NR (2012) Risk and reward are processed differently in decisions made under stress. Curr Dir Psychol Sci 21(1):36-41

Milinski M, Sommerfeld RD, Krambeck HJ, Reed FA, Marotzke J (2008) The collective-risk social dilemma and the prevention of simulated dangerous climate change. Proc Natl Acad Sci 105(7):2291-2294

Morgan MG, Fischhoff B, Bostrom A, Atman CJ (2002) Risk communication: a mental models approach. University Press, Cambridge

Morton TA, Rabinovich A, Marshall D, Bretschneider P (2011) The future that may (or may not) come: how framing changes responses to uncertainty in climate change communications. Glob Environ Chang 21(1):103-109. https://doi.org/10.1016/j.gloenvcha.2010.09.013

Pedroni A, Frey R, Bruhin A, Dutilh G, Hertwig R, Rieskamp J (2017) The risk elicitation puzzle. Nat Hum Behav 1(11):803

Pratt JW (1992) Risk aversion in the small and in the large. In: Foundations of Insurance Economics, Springer, pp 83-98

Santos FC, Pacheco JM (2011) Risk of collective failure provides an escape from the tragedy of the commons. Proc Natl Acad Sci 108(26):10,421-10,425. https://doi.org/10.1073/pnas.1015648108

Shyu WM, Grosse E, Cleveland WS (2017) Local regression models. In: Statistical models in S, Routledge, pp 309-376

Steffen W, Rockström J, Richardson K, Lenton TM, Folke C, Liverman D, Summerhayes CP, Barnosky AD, Cornell SE, Crucifix M, Donges JF, Fetzer I, Lade SJ, Scheffer M, Winkelmann R, Schellnhuber HJ (2018) Trajectories of the earth system in the anthropocene. Proc Natl Acad Sci 115(33):8252-8259. https://doi.org/10.1073/pnas.1810141115

Sterman JD (2008) Risk communication on climate: mental models and mass balance. Science 322:532-533. https://doi.org/10.1126/science.1162574

Stocker TF (2013) The closing door of climate targets. Science 339(6117):280-282. https://doi.org/10.1126/ science. 1232468

Tavoni A, Dannenberg A, Kallis G, Löschel A (2011) Inequality, communication, and the avoidance of disastrous climate change in a public goods game. Proc Natl Acad Sci 108(29):11,825-11,829. https://doi.org/10.1073/pnas.1102493108

Teigen KH, Juanchich M, Riege AH (2013) Improbable outcomes: infrequent or extraordinary? Cognition 127(1):119-139

World Values Survey Association (2014) World values survey wave 6 2010-2014. http://www. worldvaluessurvey.org/WVSDocumentationWV6.jsp, official Aggregate v.20150418. Asep/JDS, Madrid SPAIN

Publisher's note Springer Nature remains neutral with regard to jurisdictional claims in published maps and institutional affiliations. 